\title{
Comparing Training Techniques in Personal Protective Equipment Use - ERRATUM
}

\author{
Richard J. Salway, MD, MScDM; ${ }^{1,2}$ Trenika Williams; ${ }^{3}$ Camilo Londono; ${ }^{4}$ Patricia Roblin, MS; ${ }^{4}$ \\ Kristi Koenig, MD; ${ }^{5}$ Bonnie Arquilla, $\mathrm{MD}^{4}$
}

1. New York Health and Hospitals, Office of Quality and Safety, New York, New York, USA

2. Kings County Hospital Center, Department of Emergency Medicine, Brooklyn, New York, USA

3. Geisel School of Medicine at Dartmouth, Hanover, New Hampshire, USA

4. SUNY Downstate College of Medicine, Brooklyn, New York, USA

5. Center for Disaster Medical Sciences, University of California - Irvine School of Medicine, Irvine, California, USA

Keywords: disasters; emergencies; emergency medicine; personal protective equipment; preparedness; training; erratum

doi:10.1017/S1049023X20000667

(C) World Association for Disaster and Emergency Medicine 2020.
https://doi.org/10.1017/S1049023X20000564; Published by Cambridge University Press: 11 May 2020.

Salway RJ, Williams T, Londono C, Roblin P, Koenig K, Arquilla B. Comparing training techniques in personal protective equipment use - ERRATUM. Prehosp Disaster Med. 2020;35(4):472.

In the original publication of this article, the year in the revised and accepted dates appeared incorrectly. The correct history dates for this article are:

Received: November 9, 2019

Revised: January 20, 2020

Accepted: January 28, 2020

The publisher apologizes for this error.

Reference

1. Salway RJ, Williams T, Londono C, et al. Comparing training techniques in personal protective equipment use. Prehosp Disaster Med. 2020;35(4):XX-XX. 